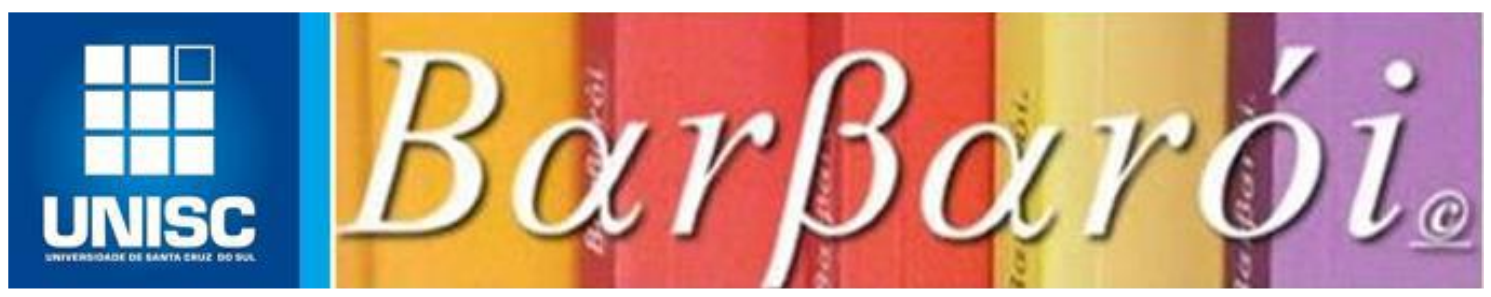

\title{
UMA ETNOGRAFIA DA ATENÇÃO À SAÚDE MENTAL DE SUJEITOS EM SITUAÇÃ̂ DE RUA
}

DOI: http://dx.doi.org/10.17058/barbaroi.v0i0.13973

\author{
Eneida Santiago \\ Universidade Estadual de Londrina - UEL - Brasil \\ Lucielly Santos \\ Universidade Estadual de Londrina - UEL - Brasil
}

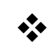

\section{Resumo}

Este artigo propõe uma reflexão sobre a intersecção entre duas questões: a atenção à saúde mental e aos sujeitos em situação de rua. Na confluência dessas questões, o sujeito em situação de rua coloca um significativo desafio para os serviços de saúde mental sobre como contemplálos de forma integral, considerando e respeitando suas singularidades. A partir disso, temos como objetivo principal, nesta pesquisa, delinear e problematizar, na visão dos sujeitos em situação de rua, como a atenção em saúde mental, a partir das políticas públicas, contemplam suas especificidades de demandas e necessidades e como essas proposições se efetivam, ou não, na prática de um serviço de saúde mental. O território escolhido foi o Centro de Referência Especializado para a População em Situação de Rua (Centro Pop). Como estratégia para o trabalho de campo, utiliza-se a perspectiva etnográfica como orientadora do estar no campo. Evidenciaram as nossas conversas que os sujeitos em condição de desabrigo, em sua maioria, raramente procuram o serviço de saúde mental e apresentam o testemunho de como o serviço de saúde mental não conseguiu deslocar a hegemonia das práticas orientadas pelo modelo médico tradicional para o modelo psicossocial de atendimento.

Palavras-chave: Sujeito em situação de rua; Saúde mental; Centro Pop; Sofrimento psíquico.

\section{Introdução}

Este artigo apresenta uma pesquisa que discute as estratégias de atenção em saúde mental disponibilizadas aos sujeitos em situação de rua a partir da perspectiva dos próprios sujeitos. Ambos os fenômenos, atenção em saúde mental e sujeito em situação de rua, configuram uma mesma e complexa problemática tanto para o poder público como para a sociedade (AMARANTE, 2000). Na confluência dessas questões apresenta-se um significativo desafio para as políticas públicas de saúde e saúde mental sobre como contemplar 
estes indivíduos de forma integral, considerando e respeitando suas singularidades de cuidado e de existência.

Estar na rua impõe desafios para que a vida se sustente em seus diversos processos e exigências, como a sociabilidade, os laços de amizade, a manutenção da integridade física e segurança pessoal, o acesso à alimentação, o uso abusivo de substâncias, os cuidados de saúde, entre outros. Nos interessava, nesta pesquisa, escutar os próprios sujeitos em situação de rua sobre como articulavam esses variados aspectos e de que forma percebiam e contemplavam serviços de saúde e saúde mental nesses possíveis encaixes. Com tais propósitos, fizemos uma imersão etnográfica em um Centro de Referência Especializado para a População em Situação de Rua (Centro Pop), em que conhecemos e convivemos com homens e mulheres que por ali passavam.

\section{Percurso metodológico}

A trajetória da pesquisa se sustentou em uma perspectiva etnográfica como orientadora para a experiência no campo e o olhar sobre pessoas e histórias encontradas. A escolha pela etnografia se fez por ela se propor a produzir, a partir de um fenômeno social ou de um coletivo de pessoas:

[...] um olhar de perto e de dentro, mas a partir dos arranjos dos próprios atores sociais, ou seja, das formas por meio das quais eles se veem para transitar pela cidade, usufruir seus serviços, utilizar seus equipamentos, estabelecer encontros e trocas nas mais diferentes esferas [...]. Esta estratégia supõe um investimento em ambos os polos da relação: de um lado, sobre os atores sociais, o grupo e a prática que estão sendo estudados e, de outro, a paisagem em que essa prática se desenvolve, entendida não como mero cenário, mas parte constitutiva do recorte de análise (MAGNANI, 2002, p. 18).

A perspectiva etnográfica pressupõe aproximação, significa estar disposto e disponível para trocas e interlocuções ao mesmo tempo em que confrontações entre teoria do pesquisador e experiência concreta em campo são feitas (PEIRANO, 1995).

O campo escolhido para imersão foi um Centro de Referência Especializado para a População em Situação de Rua (Centro Pop) do interior do estado do Paraná. A escolha por este dispositivo deveu-se por ser uma instituição referência da área da assistência social, especificamente, na proteção social especial de média complexidade às pessoas em situação de risco pessoal e social por violação de direitos, o que demanda intervenções específicas. Os que são acompanhados pelo Centro Pop chegam por busca espontânea ou por encaminhamento de outros serviços públicos. Estando na instituição, quando em concordância, passam por atendimentos especializados, tais como atividades de cuidado pessoal, alimentação, oficinas 
temáticas, acesso às ações da promoção e assistência social, suporte e acompanhamento psicológico, bem como a oferta de outros serviços e encaminhamentos para a rede intersetorial municipal de assistência social e/ou de saúde (BRASIL, 2011).

Os participantes da pesquisa foram homens e mulheres maiores de 18 anos que frequentavam o Centro Pop, estavam em situação de rua e eram atendidos por serviços de saúde por questões relacionadas à saúde mental. A imersão no campo ocorreu, em média, em três dias por semana ao longo de cerca de seis meses. Quando em campo, a pesquisadora participava do cotidiano institucional e, entre as atividades que seriam realizadas no período, decidia aleatoriamente de qual participaria. Em algumas ocasiões, havia o planejamento de saídas para assistir algumas atividades artísticas ou passear em alguma praça, por exemplo, ocasiões em que a pesquisadora também foi participante ativa. Em todos os momentos em campo, conversas e trocas genuínas eram estabelecidos mediante a proposição de a pesquisadora efetivamente participar do cotidiano do Centro POP. As experiências da pesquisadora no campo foram registradas em diário pessoal. A pesquisa foi devidamente aprovada pelo Comitê de Ética em Pesquisa (CEP), sob parecer n. 2.695.033.

Segundo Oliveira (1998), a apreensão dos fenômenos sociais, por meio do qual o pesquisador busca compreender o universo social do outro, deve ocorrer de dentro, estando lá para ver e ouvir em sua verdadeira interioridade, conseguindo assim apreender os sentidos para a interioridade do contexto considerado e as significações trazidas para a exterioridade. Olhar e ouvir são atos primordiais no trabalho de campo, ao constituírem a percepção daquilo que a pesquisa solicita, mas será no ato de escrever, concomitante ao de pensar, que o conhecimento, singularizado, textualizará os fenômenos observados.

Com tais suportes, cabe destacar também que este estudo utilizou, ao longo de todo o trabalho de campo e análise de dados, alguns operadores analíticos de Michel Foucault (biopolítica, disciplina e normalização). Na obra Microfísica do Poder, Foucault (1978) trata das questões relacionada à biopolítica, um conceito utilizado para designar práticas que se aplicam na população a fim de controlar a vida. Já em História da Loucura, Foucault (2008) analisa o dispositivo de disciplina, que se constitui na normalização do indivíduo, adestrandoo como forma de controle e classificação. Tais operadores auxiliaram na análise da configuração do processo saúde mental, principalmente quando enfrentados por pessoas que possuem uma condição de existência considerada desviante por não se adequarem ao padrão normal predominante, como o da moradia convencional. 
A partir destes apontamentos iniciais, torna-se necessário retomar a relação da sociedade com o fenômeno da loucura nas diferentes épocas, pois considerar os olhares e as práticas dispensadas às pessoas em sofrimento psíquico ao longo da história auxilia na construção de outra compreensão de como esses sujeitos foram e são contemplados, ou não, pelas políticas públicas de saúde mental nos dias atuais. Para tanto, realizaremos um percurso histórico, identificando, em síntese, alguns acontecimentos que destacamos como sendo contribuintes para o campo da saúde mental. Iniciamos evidenciando a representação da loucura na era clássica, em que tal fenômeno era tolerado e tinha outro sentido.

Foucault (2008) aponta que, na era clássica, do século V a.C. até o século V d.C., a loucura foi entendida socialmente como manifestação divina; dessa forma, os loucos andavam livres pelas cidades, não sendo vistos como uma problemática. A loucura nem sempre foi vista sob o olhar médico; antes do advento do Estado Moderno (século XVIII), quando o discurso psiquiátrico não tinha se apropriado da insanidade, esta era concebida como uma forma de expressão do sujeito. O tema, que atualmente é tão controverso, foi objeto de diversas explicações, passando por desde o campo da mitologia até o da religião. Neste sentido, o louco foi apontado como uma pessoa portadora de poderes diversos. O que falava era ouvido como um saber significativo e fundamental, capaz de interferir no destino das pessoas. A loucura era compreendida como uma revelação dos deuses, assim sendo reconhecida e valorizada socialmente por algumas pessoas, principalmente por figuras religiosas como os padres, não havendo necessidade de seu controle e/ou exclusão social (FOUCAULT, 2008).

No entanto, no final do século XVIII, em 1793, o médico Phillip Pinel, tendo sido nomeado para dirigir o Hospital Bicêtre, na França, estabeleceu uma nova condição social para a loucura. Tratava-se da apropriação da loucura pelo saber médico. A partir de então, a loucura passou a ser sinônimo de doença mental. Dessa forma, deixou de ocupar o âmbito social e político e foi incorporada à teoria científica do campo do saber da medicina, em especial, a psiquiatria. Neste contexto, se estabeleceu uma situação emblemática: se, por um lado, a psiquiatria privilegiava a loucura como sendo pertencente ao campo exclusivo da ciência médica, dado que a assistência clínica passou a ser de sua responsabilidade, por outro lado, negou ao louco o status de sujeito e, como tal, de cidadão. Ao confinar a loucura aos asilos, privou-se o louco do direito de voz, reconhecimento social e subjetivo, concebendo a ele o lugar de insano, sendo apenas um objeto de estudo da psiquiatria (FOUCAULT, 2008; AMARANTE, 2007). Diante dessa terapêutica dominante realizada no manicômio, cujos propósitos estavam calcados no saber psiquiátrico, evidenciou-se, no lugar de tratar, a necessidade de colocar Barbarói, Santa Cruz do Sul, n.55, p.<81-101>,jul./dez. 2019 
ordem no social, ou seja, o hospício passou a se apresentar com uma função saneadora, disciplinar e moralizante (AMARANTE, 2007), sentidos dominantes na compreensão e no tratamento da doença mental por um período considerável, até que reflexões e experiências contra-hegemônicas refletiriam mudanças no objetivo da psiquiatria, do tratamento da doença mental para a promoção da saúde mental (BIRMAN; COSTA, 1994).

No Brasil, por volta de 1970, questionamentos e denúncias quanto às condições cronificantes e $\quad$ ineficientes dos tratamentos dispensados aos loucos iniciaram movimentações pela mudança do modelo de atenção em saúde mental até então vigente no país, processo este denominado por Reforma Psiquiátrica. O discurso foi em prol de mudanças dos modelos dominantes de atenção, até então marcado pela segregação social e política dos indivíduos considerados adoecidos, assim como por uma assistência asilar quase exclusivamente hospitalocêntrica (AMARANTE, 2000). Importantes ações foram realizadas, em especial, ao que se referia a melhoria qualitativa da atenção em saúde mental às pessoas em sofrimento psíquico. No entanto, a dimensão do cuidado era apenas uma das questões que envolvem tal problemática e não deve ser compreendida como a mais importante. Além de cuidados integrais para estes sujeitos muitas vezes esquecidos na sociedade, fazse necessário, de forma concomitante com a reflexão sobre outros componentes do fenômeno da loucura, a constituição de mudanças efetivas no aparato jurídico sobre aqueles em sofrimento psíquico intenso (BRASIL, 2005).

Apesar das movimentações no processo pela Reforma Psiquiátrica, expressivas mudanças ocorreram com a homologação, no país, da Lei Federal n.10.216/2001 (BRASIL, 2001). Tal legislação orienta que a atenção às pessoas em sofrimento psíquico deveria ser construída através de ações que objetivassem a reinserção, o fortalecimento da contratualidade e dos laços sociais, por meio do resgate e do exercício da autonomia, da cidadania, dos vínculos familiares, do acesso à cidade, ao trabalho e aos espaços e processos coletivos que a vida em comunidade poderia propiciar. O processo pela Reforma Psiquiátrica brasileira caminhou significativamente em sua implementação, o que é perceptível a partir de variadas dimensões, como na aprovação de uma ampla legislação voltada à garantia dos direitos dos sujeitos em sofrimento psíquico, bem como uma expansiva inserção e disponibilização de ações e estratégias, como desdobramentos da política pública de saúde mental, nos serviços e dispositivos territoriais em várias regiões do país em substituição às instituições manicomiais. Destaca-se que alguns dispositivos de saúde apresentam experiências exitosas nas ações ofertadas para os usuários, quando, por exemplo, atuam desconstruindo o saber unilateral do profissional de saúde, a não culpabilização do sujeito pela sua condição, Barbarói, Santa Cruz do Sul, n.55, p.<81-101>,jul./dez. 2019 
permitindo que os usuários sejam cogestores na construção de seu cuidado. Tais posturas são aqui valorizadas. Contudo, é preciso destacar que essas experiências positivas podem e precisam ser impulsionadas pela implementação de políticas públicas de saúde e de saúde mental que abranjam não um ou outro indivíduo, mas toda a população, bem como questões específicas (VARANDA; ADORNO, 2004).

É pela necessidade do enfrentamento de alguns desafios no campo da saúde mental que esta pesquisa ganha contornos. As temáticas sujeitos em situação de rua e atenção em saúde mental são os protagonistas neste estudo que problematiza não somente às precariedades e vulnerabilidades de saúde e vida desses sujeitos, mas também os desafios de construção de práticas que contemplem as condições existenciais desses indivíduos, viabilizando seu acesso aos serviços de saúde disponíveis, o que se faz fundamental para minimizar o sofrimento desses indivíduos nas ruas (VARANDA; ADORNO, 2004).

Em vista disso, considera-se que as pessoas que estão em situação de rua sofrem variadas formas de violações. Suas realidades não condizem com o disposto pelo ordenamento jurídico do país, consoante à Constituição Federal de 1988, que, em seu Capítulo II, dos direitos sociais, no Artigo $6^{\circ}$, assegura à saúde, à alimentação, ao trabalho, à moradia, ao lazer, à segurança, à previdência social, a proteção à maternidade e à infância, à assistência aos desamparados (BRASIL, 1988). Dessa forma, evidenciamos, nesta discussão, a necessidade e o desafio para as políticas públicas de saúde e de saúde mental integrarem a todos, inclusive as pessoas com condições de vida particulares como os sujeitos em situação de rua, tendo em vista os princípios da universalidade, equidade e integralidade preconizados pelo Sistema Único de Saúde (SUS) (BRASIL, 1990).

A Política Nacional para a População em Situação de Rua define o coletivo desses indivíduos como um:

[...] grupo populacional heterogêneo que possui em comum a pobreza extrema, os
vínculos familiares fragilizados ou rompidos e a inexistência de moradia convencional
regular. Essa população se caracteriza, ainda, pela utilização de logradouros públicos
(praças, jardins, canteiros, marquises, viadutos) e áreas degradadas (prédios
abandonados, ruínas, carcaças de veículos) como espaço de moradia e de sustento, de
forma temporária ou permanente, bem como unidades de serviços de acolhimento
para pernoite temporário ou moradia provisória (BRASIL, 2009, p. 01).

Diante de tal caracterização, percebemos como as pessoas em situação de rua desafiam os princípios do SUS. O grande número de brasileiros nessa circunstância denuncia as contradições de uma sociedade que tem a seguridade social como direito constitucional e, além disso, firma a saúde como direito de todos e dever do Estado, mas mesmo diante dessas garantias legais, ainda permite que pessoas não são contempladas pelas políticas sociais, em 
especial, as políticas públicas de saúde (BRASIL, 2014). Interno ao fenômeno da vida nas ruas, há ainda uma dimensão mais específica, a dos sujeitos que estão desabrigados e apresentam sofrimento psíquico intenso, condição que pouco é contemplada pelas propostas governamentais. Para Ferraz (2000), o sujeito em situação de rua em sofrimento psíquico é quem vive a experiência da loucura em estado livre. Trata-se daquele que está fora do hospital psiquiátrico ou de outros dispositivos de suporte permanente e não usufrui do suporte de familiares, que muitas vezes não existem mais. Nesse caso, além de estar impregnados pelas marcas que são atribuídas às pessoas em situação de rua, eles recebem também outro rótulo: o da loucura. São pessoas que apresentam um aspecto mais complexo, o sofrimento psíquico. Essas, em especial, carecem de uma política pública consistente.

Frente às realidades que marcam o fenômeno social do sujeito em situação de rua, desponta a necessidade de se dar visibilidade para sua existência, bem como qualificar o atendimento de suas demandas. Dessa forma, estamos diante de uma problemática coletivamente relevante, que são os sujeitos que têm seus direitos básicos prejudicados. A sua condição de vida é marcada por insuficiências sociais que tensionam o Poder Público para um processo de construção de reconhecimento e garantias das necessidades básicas desses sujeitos, elevando-os, mesmo que gradualmente, para uma situação de acesso e exercício da cidadania.

\section{Apresentação e discussão dos dados}

As vivências da pesquisadora no cotidiano institucional do Centro de Referência Especializado para a População em Situação de Rua (Centro Pop) serão apresentadas a partir de eixos analíticos. Tal organização foi escolhida por entendermos ser ela uma boa forma de comunicar os dados do estudo a partir da retomada do campo e posterior teorização. Os eixos analíticos constituídos são: assistência social como porta de entrada dos sujeitos em situação de rua nos serviços de saúde mental; quem são os sujeitos em situação de rua acompanhados pelo serviço de saúde mental; desafios no acesso do sujeito em situação de rua ao serviço de saúde mental; o olhar dos sujeitos em situação de rua sobre o serviço de saúde mental.

A maioria dos discursos aqui colocados foram extraídos de conversações com os atendidos pelo Centro Pop no decorrer das atividades diárias. De modo geral, são conversas realizadas voluntariamente entre pesquisadora e sujeitos sem nenhuma provocação mais diretiva, já que desejávamos viver o cotidiano da instituição. Nesta perspectiva, no território a pesquisadora ofereceu uma escuta atenta e curiosa a quaisquer conversas que pudessem vir à tona, mesmo que elas, a princípio, não fossem de temática diretamente relacionada com nossos 
objetivos. Assim, apesar da riqueza de dados e história a que tivemos acesso ao longo de meses de imersão em campo, aqui privilegiamos as narrativas relacionadas com o tema de estudo, ou seja, as estratégias de atenção à saúde mental disponibilizadas para o sujeito em situação de rua quando ele vivencia o sofrimento psíquico. Em nossas discussões explicitamos fragilidades e pontos de força que estão no cotidiano dos serviços de saúde mental.

A noção da pessoa em situação de rua como um sujeito de desejo será incorporada neste texto a partir dos discursos dos atores sociais participantes da pesquisa. Para uma melhor contextualização, será apresentada a primeira letra do nome, o sexo e faixa etária daqueles que aqui citaremos. Aproveito para justificar que, nas páginas a seguir, passo a usar o verbo na primeira pessoa do singular e até mesmo o pronome pessoal minha. Considero importante destacar essa escolha ao leitor para explicitar que ressalto situações que estão diretamente relacionadas às minhas experiências, aos meus sentimentos, percepções e afetações em mim suscitadas no território de pesquisa.

\section{Quem são os sujeitos em situação de rua atendidos pelo serviço de saúde mental?}

A imersão no campo se iniciou um dia antes mesmo que eu adentrasse o Centro POP. Tinha chovido muito durante a noite toda; nos arredores da instituição havia várias pessoas com as roupas ensopadas, as quais percebi com um desconforto solidário aos que provavelmente estariam com frio, já que estávamos no inverno. De manhã, costumeiramente, desejamos um bom dia para quem encontramos na rua e nos lugares. Neste começo de dia, uma sexta-feira, a expressão bom dia se engasgou em minha garganta, mas, mesmo assim, segui e entrei na instituição. A primeira pessoa a quem me aproximei naquele dia tinha ficado desabrigada em uma noite de chuva e frio, tossindo e molhada... como desejar bom dia? Bom dia para quem? Assim, de forma costumeira, começava o dia das dezenas de pessoas que aguardavam na fila pelo início das atividades no Centro Pop. A narratival a seguir foi realizada para a pesquisadora por uma dessas pessoas que aguardavam o funcionamento do serviço.

"Sabe o que afunda todo morador de rua? É a droga. Fumo crack e por conta da pedra eu perdi a família. Eu não consigo deixar de usar o crack, eu sinto falta quando fico dias sem usar” (M., Sujeito em situação de rua do sexo masculino, faixa etária de 40 anos - Diário de Campo, 08/2018). 
A temática "uso de álcool e outras drogas" surge com frequência na fala dos sujeitos em situação de rua como algo considerado primordial que atuaria como um mantenedor da vida nas ruas. Deste modo, encontramos dados similares com os de Barreto e Fernandes (2000), que apontam o uso das substâncias psicoativas estar intimamente ligado ao fenômeno social do viver nas ruas; muitas vezes, aliás, com uma relação abusiva com as drogas antes da ida para a rua.

Voltando para o sujeito citado, após o estabelecimento de laços que nos aproximaram, ele compartilhou:

"Uso álcool e drogas, não consigo ficar sem. Choro todos os dias, pensando nos meus filhos [que também estão em situação der rua]. Choro por estar nessa vida. Eu que sempre trabalhei, pela igreja ajudava os moradores de rua, agora eu estou nessa condição (M., Sujeito em situação de rua do sexo masculino, faixa etária de 40 anos - Diário de Campo, 08/2018).

$\mathrm{Na}$ visão de outro sujeito que está em processo de superação das ruas, enquanto conversava comigo no caminho a uma atividade artística que ocorreu fora da instituição, a oferta de esmola para aquele que está na rua só estará contribuindo para a sua permanência e, mesmo, alguns que recebem oportunidade de mudança da condição de rua têm preferência em continuar na mesma situação.

"Tem muita gente que quer ficar igual zumbi, não quer sair dessa vida” (J., Sujeito em situação de rua do sexo masculino, faixa etária de 20 anos - Diário de Campo, 09/2018).

Todavia, pergunto: quando não se pode escolher a comida que come ou a roupa que se veste, o exercício da vontade não fica bastante comprometido? As particularidades das experiências de cada um e de como cada pessoa reage aos efeitos de sua trajetória de ida para rua e depois que se instalam nesse espaço parecem impedir generalizações. Além disso, J. parece expressar, quando diz que "tem gente que quer ficar igual zumbi", uma lógica do imaginário social que fez com que alguns passassem a ver os sujeitos em situação de rua como os novos desviantes da sociedade, como perigosos, devido ao seu consumo de crack, álcool e outras drogas, e porque perambulam pelas ruas pedindo ou até mesmo roubando para sustentar o uso abusivo das substâncias, deixam de ser sujeitos desejantes para serem meros objetos inertes e irresponsáveis pelos seus próprios atos (MERHY, 2012). 
Essas pessoas que vivem nas ruas, sem ganho definido, ainda com uma situação agravada pela contínua permanência em condições insalubres, sujeitas à violência ou, ainda, sob a ação contínua de álcool e drogas, são vistas, nas sociedades urbanizadas, como uma presença inoportuna e ameaçadora (MERHY, 2012). O coletivo formado pelos sujeitos em situação de rua, quando ocupantes de espaços públicos, como praças, em qualquer cidade, podem ser rotulados como os novos anormais à luz do pensamento foucaultiano na atualidade. Esses sujeitos vêm se tornando um público-alvo para um medo atávico pelo não controlado, levando de roldão qualquer tipo de movimento que se alie a uma aposta em uma vida livre, e são considerados, no imaginário social, como vítimas da captura que as substâncias químicas ilícitas provocariam (MERHY, 2012). Todavia, a concepção que não reconhece o sujeito em situação de rua como humano se esquece da variedade de condições que permeiam essa problemática social, e conhecer tais fatores favorece a ampliação da visão acerca da temática.

O tópico a seguir se refere aos desafios ligados ao serviço de saúde mental. Serão integradas as considerações dos profissionais do serviço assistencial Centro Pop sobre as características do serviço de saúde mental que limitam seu uso pelos sujeitos em situação de rua.

\section{Desafios no acesso do sujeito em situação de rua ao serviço de saúde mental}

Um profissional do Centro Pop2 fez um apontamento que consideramos importante sobre o serviço de saúde mental:

"[N]o CAPS está previsto o atendimento a toda população, inclusive do sujeito em situação de rua. Mas, o CAPS não vai até a rua onde o sujeito está. Eles ficam nos viadutos próximos ao Centro Pop na região central, então não vão ao CAPS por conta da distância. O CAPS poderia sair para a rua, mas se sair quem substitui a técnica de lá, que trabalha não somente com a população em situação de rua, como também [com] outras demandas" (Profissional do Centro Pop - Diário de Campo, 07/2018).

A fala do profissional destaca a importância de a equipe estar onde as pessoas estão, que, neste caso, é a rua, construindo novos projetos de vidacom essas pessoas, ofertando atenção e suporte nesse contexto. Pensamos que o território pode trazer benefícios para a relação profissional e usuário; especialmente para o profissional, pode possibilitar uma percepção da relação do sujeito com a droga em suas complexidades, incorporando a Barbarói, Santa Cruz do Sul, n.55, p.<81-101>,jul./dez. 2019 
experiência de vida dessas pessoas e seu local de moradia/estadia na rua na constituição de novas ações em saúde mental. Não pensar ou poder acessar o território como um espaço potente para a atuação profissional pode indiretamente contribuir para uma rede em saúde mental por vezes já enfraquecida e para movimentos de aproximação com o hospital psiquiátrico como recurso de tratamento. Parece que o que sobra é a velha fórmula aplicada aos anormais e perigosos: de abandono em abandono reside o destino esperado do hospital psiquiátrico, as ruas higienizadas, a exclusão como medida de segurança e o isolamento como medida terapêutica (LISBOA, 2013).

Frente a todas as necessidades vivenciadas pelo sujeito em situação de rua, sejam elas de ordem material, relacional ou emocional, o hospital parece virar a solução para todas as carências quando as outras intervenções se encontram enfraquecidas. Nesta discussão, interrogamos as internações que ocorrem sem chances de acolhimento ao longo de suas estadias nas ruas, chances de escuta das suas dificuldades, chances de ações que pudessem, de fato, evitar o percurso de exclusão, para realizar intervenções que considerem e busquem o estabelecimento de estratégias de cuidados mais apropriados às necessidades dessas pessoas (LISBOA, 2013).

Chamamos atenção, neste momento de análise, para um tipo de processo de trabalho que não se vincula ao contexto interno do serviço de saúde como única alternativa de atendimento, mas que aposta no território como possibilidade de um outro espaço de cuidado. Um trabalho itinerante que busca maior cobertura de ações de atenção na tentativa de alcançar grupos sociais com dificuldades de acesso aos serviços e de criação de vínculos, como é o caso do sujeito em situação de rua, que dificilmente se adapta aos modelos tradicionais de atendimento nos serviços de saúde (SILVA, 2014). Este processo de trabalho seria o do consultório na rua, criado no âmbito do Sistema Único de Saúde para produzir cuidados aos sujeitos em situação de rua a partir de duas vias: a constituição de projetos terapêuticos singulares para cada pessoa e cada coletivo nesta situação e, em concomitância, problematizar os modos de cuidado que atravessam a rede de assistência (LONDERO; CECCIM; BILIBIO, 2014).

Dois profissionais do Centro Pop expressaram suas visões sobre a pouca utilização dos serviços de saúde mental pelos sujeitos em situação de rua. Em conversa comigo quando do esclarecimento sobre os objetivos desta pesquisa, os profissionais compartilharam sua percepção: 
"Não acredito que eles querem recuperação, acredito que eles não vão até o CAPS ad, porque não querem” (Profissionais do Centro Pop - Diário de Campo, 07/2018).

Um sujeito em situação de rua, em fragilidade psíquica, que aceita cuidado em um momento a partir da insistência de uma equipe de abordagem de rua, mas posteriormente muda de ideia quanto ao cuidado e se recusa a ir até a instituição de saúde mental comumente é responsabilizado pela equipe de profissionais e identificado como alguém que de fato não queria atendimento, processo este dificilmente pensado como algo que poderia ser produzido além das fronteiras do serviço. Assim, parece que o enfrentamento da problemática depende mais do sujeito em situação de rua, como se o serviço de saúde mental já tivesse feito o que seria de sua competência.

A temática a seguir ainda discorre sobre o serviço de saúde mental, mas esta discussão contempla a visão de quem vive nas ruas e utiliza os serviços de saúde mental. Esta é parte de uma conversa de A., que, naquele momento, estava em processo de superação das ruas, isto é, estava estudando e realizava pequenos trabalhos, como capinagem; com a remuneração alugou um cômodo para morar e queria fazer faculdade. A. passou por atendimento pelo CAPS ad ao longo de quatro anos. Nesse período, o CAPS ad era localizado na região central do município, o que facilitava o acesso para ele, pois seu território de estadia era próximo ao serviço. A. acreditava que toda região da cidade necessitava de um serviço de saúde mental, mas com a mudança do dispositivo para uma zona da cidade muito distante do centro, ele acreditava que, para os sujeitos da área central, tinha ficado muito mais difícil buscar o serviço. Afirmava que, em sua opinião, gostaria que os poderes públicos investissem em mais serviços, mas sabia que isso seria muito difícil de acontecer. Entretanto, observava que o número de pessoas nas ruas só aumentava e, com isso, também crescia a demanda de utilização do CAPS ad, havendo pouco investimento de recursos públicos para ampliar a capacidade do serviço.

“Essas pessoas não acessavam o serviço, por vários motivos, acessibilidade, por falta de interesse até pelo momento psicológico que eles viviam, mas também existe o fato que o serviço não busca essas pessoas" (A., Sujeito em situação de rua do sexo masculino, faia etária de 40 anos - Diário de Campo, 12/2018).

O relato de A. aponta para algumas compreensões a respeito da pergunta realizada por um dos profissionais do Centro Pop, a da razão de os sujeitos em situação de rua Barbarói, Santa Cruz do Sul, n.55, p.<81-101>,jul./dez. 2019 
"resistirem" a acessar o serviço de saúde mental CAPS ad. A. faz considerações que apontam para algumas limitações do serviço que atuariam como impedimento para a procura por cuidado em saúde mental pelo sujeito em situação de rua, sugerindo, a partir de uma análise legítima, a indicação do território da rua como um espaço potencial de atuação do CAPS ad. A localização do serviço de saúde mental pode ser um dificultador no processo de procura e conquista do cuidado desse público (BORYSOW; FURTADO, 2013) e, ao nos referirmos a isso em articulação com a sugestão de A., cabe resgatar as diretrizes do Ministério da Saúde, que propõem o acolhimento do sujeito em sofrimento psíquico e, entre eles, o sujeito em situação de rua, na comunidade por meio dos serviços descentralizados e territorializados, tendo a clareza de que a "[...] construção de uma rede comunitária de cuidados é fundamental para a consolidação da Reforma Psiquiátrica" (BRASIL, 2005, p. 25).

Fechamos a discussão sobre esta temática com outro relato de A., pois tive a oportunidade de com ele firmar longas conversas sobre o CAPS ad. Quanto às práticas de cuidado em saúde mental e a dificuldade de elas contemplarem a heterogeneidade dos indivíduos em situação de rua, ele diz:

“Frequentei por quatro anos [no CAPS ad], de 2010 a 2014. Mas, tive alta. Busquei o serviço, porque eu percebi que os meus hábitos não eram benéficos e favoreciam a dicção. Foi muito bom pra mim, o atendimento do serviço, os funcionários, as psicólogas, os assistentes sociais, teve também um certo acompanhamento psiquiátrico, toda a rede do CAPS ad foi muito útil para a minha progressão mental que hoje está no nível controlado, graças ao atendimento do serviço. O CAPS ad foi muito útil pra mim, e eu queria que fosse útil para outras pessoas também” (A., Sujeito em situação de rua do sexo masculino, faixa etária de 40 anos - Diário de Campo, 12/2018).

O CAPS se apresenta como o principal dispositivo para a implantação da atual política de Saúde Mental. Todavia, muitos dos equipamentos ainda estão distantes do que é delineado pelo modo de Atenção Psicossocial, cuja ética implica a ousadia de buscar o novo, visando superar o paradigma asilar já conhecido, discutido no primeiro capítulo deste trabalho (YASUI; COSTA-ROSA, 2008).

Um profissional do CAPS ad em diálogo realizado com um profissional do Centro Pop e na presença de um atendido pelos dois serviços (CAPS ad e Centro Pop) disse: 
“A solução não é trazer o CAPS ad para o centro, porque lá na zona norte tem muitas pessoas que procuram atendimento. A solução é construir outro aqui no centro" (Profissional do CAPS ad-Diário de Campo, 08/2018).

A partir da fala do profissional do serviço de saúde mental, recordei de uma narrativa de um técnico do Centro Pop que dizia sobre um barracão que estava sendo construído para funcionar como um centro dia para o sujeito em situação de rua na área central de Londrina. No entanto, sem nenhuma explicação para os usuários nem para os cuidadores desse público, a obra não foi inaugurada. Para o trabalhador do serviço social, alguns vizinhos poderiam ter pedido para não ter o barracão, pois incomodaria à vizinhança ter os sujeitos em situação de rua transitando nas redondezas e, por isso, pararam a obra naquele momento. $O$ técnico ainda observa que em todo lugar é assim: os vizinhos não permitem que essas pessoas fiquem, eles são jogados de um lado para o outro.

Assim, retomo a fala do profissional do CAPS ad e concordo que se faz necessário o referido dispositivo de saúde mental na região central, mas será que é de interesse do poder público realizar essa construção? Leornardis (1998) salienta o caráter classista da instituição manicomial, destinada à expulsão e repressão dos setores mais pauperizados da população, das classes consideradas marginais e, portanto, perigosas. Ainda nos dias atuais, encontramos a mesma lógica de pensamento que destina às pessoas consideradas pobres serviços sem levar em consideração as necessidades do grupo social, exacerbando os pontos de fragilidades que limitam o acesso ao atendimento e acompanhamento no serviço da rede pública de saúde mental.

Diante disso, apontamos a pouca sustentação do sofrimento psíquico intenso no território. Nossa experiência tem demonstrado que as pessoas que vivem pelas ruas, quando começam a importunar a sociedade, são, na maioria das vezes, recolhidos por guardas municipais, que os levam para o Centro Pop ou para os outros serviços da rede, reproduzindo uma forma sutil e com uma tecnologia sofisticada a mesma lógica de exclusão e controle (YASUI; COSTA-ROSA, 2008).

Outro profissional do Centro Pop também fez comentários sobre tais desafios:

"No CAPS está previsto o atendimento a toda população, inclusive do sujeito em situação de rua. Mas, o CAPS não vai até a rua onde o sujeito está. Eles [os sujeitos em situação de rua] ficam nos viadutos próximos ao Centro Pop na região central, então não vão ao CAPS por conta da distância. O CAPS poderia sair para a rua, mas se sair quem substitui a técnica Barbarói, Santa Cruz do Sul, n.55, p.<81-101>,jul./dez. 2019 
de lá que trabalha não somente com a população em situação de rua, como também outras demandas?” (Profissional do Centro Pop - Diário de Campo, 07/2018).

O cuidado produzido no CAPS ad também foi problematizado por alguns sujeitos durante nossa permanência no campo de pesquisa. Chamamos atenção para uma narrativa que dizia que a ênfase na forma de tratamento medicamentosa no serviço de saúde mental inviabiliza a sua aderência na atenção em saúde mental.

“Eu não vou no CAPS ad, para sair de uma droga e entrar em outra droga, lá eles me enchem de medicamento. Eu prefiro continuar na droga que estou. Não é pra mim isso não, eu não vou lá pra eles mandarem eu tomar remédio se eu não quero usar" (J., Sujeito em situação de rua do sexo masculino, faixa etária de 20 anos - Diário de Campo, 07/2018).

Diante deste relato emergem algumas indagações. Será que, para o sujeito que vive nas ruas, que tem nas substâncias psicoativas um mecanismo que colabora para suportar as vulnerabilidades desse espaço público, o tratamento medicamentoso seria uma terapêutica viável?

Uma comunicação aberta entre psiquiatra, bem como da equipe do serviço de saúde, e o usuário facilitaria uma prescrição mais adequada possível ao estilo de vida desse grupo social?

Durante a pesquisa de campo, ouvi várias vezes as pessoas que passam por atendimento no Centro Pop dizer que não vão ao CAPS ad porque não querem sair de uma droga e entrar em outra. Vale dizer que a prescrição medicamentosa realizada pelo psiquiatra compõe o tratamento terapêutico disponibilizado pelo CAPS ad. São receitados medicamentos como rivotril e fluoxetina para tratar principalmente quadros depressivos e de ansiedade relacionadas ao consumo de álcool e outras drogas. Remédios que também podem ser receitados durante o período de abstinência. Todavia, as pessoas com quem eu conversei fazem a observação de que ficariam dependentes de outra droga, que seria o medicamento, e ainda acreditam que alguns medicamentos controlados em interação com o álcool ou substâncias psicoativas podem gerar efeitos indesejados, assim como aumentar a dose do medicamento no organismo, do que compreendem que ingerir tais substâncias enquanto há uso de medicamento pode levar a efeitos graves.

Em razão disso, entendo que usar psicofármaco no universo social destes sujeitos que vivem em condição de desabrigo significaria uma mudança de trajetória de vida que Barbarói, Santa Cruz do Sul, n.55, p.<81-101>,jul./dez. 2019 
se configura como uma tarefa complexa. Do mesmo modo, a dificuldade em estabelecer planejamentos para a vida são fatores que podem desencorajar a procura desses sujeitos pelos serviços de saúde mental (BORYSOW; FURTADO, 2013).

Nesta perspectiva, nossos dados apresentam um testemunho de uma circunstância do serviço de saúde mental que ainda não conseguiu deslocar a hegemonia das práticas orientadas pelo modelo médico tradicional para o modelo psicossocial de atendimento. Os usuários que fazem uso do serviço Centro Pop e que estão utilizando de forma abusiva as substâncias psicoativas estão sendo orientados a buscar o serviço adequado. Mas, o fato de a maioria dos casos receber prescrição medicamentosa por parte da psiquiatria denota uma tendência preocupante e sugere que o atendimento médico neste serviço tem eliminado o espaço de ponderação sobre qual tipo de tratamento indicar para um paciente que tem demandas de necessidades específicas, como é o caso do sujeito em situação de rua (FERRAZZA; ROCHA; LUZIO, 2013). Deste modo, percebemos a junção de medicalização e atenção psicossocial como um encontro arriscado, tendo em vista que muitas pessoas que vivem em condição de rua estabelecem no uso das drogas um mecanismo de resistência ao modo de existir nesse espaço público.

Outro aspecto envolvendo o cuidado produzido pelo CAPS ad no contato do usuário com a equipe foi apontado pelos sujeitos como outro impeditivo para a procura pelo serviço.

"Estou indo no CAPS ad segunda e terça, antes eu ia quatro dias na semana, chapava a minha mente. É uma falação, eles pensam que a gente é criança. A gente passava a manhã inteira lá ouvindo eles falar sobre se cuidar quando for usar, tipo beber água e prevenir de doenças. Ficava nisso a manhã inteira, eu falava pra eles, 'isso que vocês estão explicando eu aprendi na escola, lá na segunda série'. Acha que a gente é bobo, ninguém quer morrer. Eu falava, por que vocês não usam esse tempo falando coisas mais úteis, não dando só palestra" (O., Sujeito em situação de rua do sexo masculino, faixa etária de 40 anos - Diário de Campo, 07/2018).

Nem sempre as demandas do público coincidem com os recursos disponíveis no serviço de saúde e isso é compreensível. Mas o relato me faz pensar na importância de uma comunicação aberta e flexível com o usuário. Por exemplo, na questão medicamentosa, será que o usuário está sendo orientado quanto ao objetivo terapêutico, efeitos esperados, reações adversas e cuidados na administração do medicamento. $\mathrm{O}$ ato de negociar, de refletir sobre o que está sendo disponibilizado pelo serviço e o que o usuário tem buscado e tentar ajustar as Barbarói, Santa Cruz do Sul, n.55, p.<81-101>,jul./dez. 2019 
demandas pode indicar um processo de superação de limites do tratamento tradicional em saúde mental em direção a uma prática que valorize as relações intersubjetivas na produção do cuidado, isto é, uma relação entre profissional-usuário, equipe-usuário (ANDRADE; BOSI, 2015).

Findamos esta narrativa destacando a importância do Centro Pop e sua interrelação com outros dispositivos, como o CAPS ad, no processo de reconstrução do projeto de vida do sujeito em situação de rua. Ressaltamos que a discussão não pretende se configurar como uma verdade absoluta acerca das práticas de cuidados realizadas na atenção em saúde mental, mas, antes, apontar aproximações, reflexões e alguns subsídios importantes que colaborem para aproximar o que está previsto nas políticas públicas de saúde mental às práticas de cuidados cotidianas dirigidas aos sujeitos em situação de rua.

\section{Considerações finais}

Sob uma perspectiva etnográfica, dedicamo-nos ao longo destas páginas a refletir sobre os desafios enfrentados pelos sujeitos em situação de rua quando experienciam o sofrimento psíquico intenso. Para tanto, percorremos teoricamente a relação da sociedade com a loucura nas diferentes épocas, tendo em vista que os olhares e as práticas dispensadas às pessoas em sofrimento psíquico ao longo da história nos auxilia na compreensão de como esses sujeitos foram e são, ou não, contemplados pelas políticas públicas de saúde mental nos dias atuais.

Apesar dos recentes retrocessos, apontamos que, no entendimento da pesquisadora, retrocessos que se configuram nas medidas que rompem com a política de desinstitucionalização e incentivam a hospitalização e o tratamento desumanizado, o processo da Reforma Psiquiátrica Brasileira avançou significativamente em sua implementação; as conquistas foram estabelecidas principalmente com a Lei n 10.216 de 2001 (BRASIL, 2014).

No entanto, faz-se necessário inserir na agenda da reforma psiquiátrica outras questões fundamentais, como a inviabilidade de acesso e a dificuldade técnica no atendimento nas instituições de saúde mental, considerando que, ainda, um grande contingente de pessoas não é contemplado pelos serviços em suas especificidades e demandas, inclusive, o sujeito em situação de rua (VARANDA; ADORNO, 2004).

Chegamos a algumas considerações, para finalizar esta pesquisa, de que os sujeitos em condição de desabrigo, em sua maioria, procuram raramente o serviço de saúde mental, buscando com frequência o serviço de assistência social, o que indica que o modo de trabalho nestes equipamentos sociais tem contribuído para a vinculação deste público na rede Barbarói, Santa Cruz do Sul, n.55, p.<81-101>,jul./dez. 2019 
socioassistencial. Todavia, o serviço de assistência social tem enfrentado dificuldades de articulação com os dispositivos de saúde ao lidar com os sujeitos em situação de rua quando apresentam sofrimento psíquico intenso ou demandam atenção em saúde mental devido ao uso abusivo, ou abstinência, de consumo de álcool e substâncias psicoativas (ALBUQUERQUE, 2009).

Ainda nossos dados apresentam um testemunho de uma circunstância do serviço de saúde mental que não conseguiu deslocar a hegemonia das práticas orientadas pelo modelo médico tradicional para o modelo psicossocial de atendimento.

Ao final de nossa pesquisa, vemos que o objetivo principal, qual seja, de problematizar, a partir da visão dos sujeitos em situação de rua, como as políticas públicas de saúde mental os contemplam em suas especificidades de demandas e necessidades, e, ainda, de como essas proposições se materializam, ou não, na prática cotidiana de um serviço de saúde mental, foi alcançado, sem, no entanto, ter se esgotado, o que, na verdade, não era a nossa pretensão nem, a nosso ver, algo possível.

Por fim, desejamos que estas páginas sejam alimentos para fomentar discussões e ações práticas que contribuam para a superação dos obstáculos que têm sido colocados para os sujeitos em situação de rua e para nós neste momento da história.

\title{
AN ETHNOGRAPHY OF THE STREET SUBJECT WHEN LIVING PSYCHIC SUFFERING
}

\begin{abstract}
This article proposes a reflection on the intersection between two issues: attention to mental health and the homeless. At the confluence of these issues, the homeless person poses a significant challenge to mental health services on how to fully address them, considering and respecting their uniqueness. From this, we have as main objective, in this research, to delineate and problematize, in the view of the homeless subjects, how mental health care, based on public policies, contemplates its specificities of demands and needs and how these propositions are or not, in the practice of a mental health service. The chosen territory was the Specialized Reference Center for the Homeless Population (Centro Pop). As a strategy for fieldwork, the ethnographic perspective is used to guide being in the field. It was evident from our conversations that most homeless subjects rarely seek mental health services and bear witness to how the mental health services failed to shift the hegemony of practices guided by the traditional medical model to the psychosocial model.
\end{abstract}

Keywords: Subject in street situation; Mental health; Pop Center; Psychic suffering

\section{Referências}

ALBUQUERQUE, C. M.C. Loucos nas ruas: um estudo sobre o atendimento à população de rua adulta em sofrimento psíquico na cidade do Recife. 2009. 136 p. (Dissertação) Programa de Pós-Graduação em Psicologia Dissertação (Mestrado) - Universidade Federal de 
Pernambuco, Pernambuco, 2009. Disponível em:

<https://repositorio.ufpe.br/handle/123456789/8283 >. Acesso em: 23 nov. 2019.

AMARANTE, P. Loucos pela vida: A trajetória da reforma psiquiátrica no Brasil. Rio de Janeiro: SciELO / Editora Fiocruz, 2000.

. Saúde mental e atenção psicossocial. Rio de Janeiro: Editora Fiocruz, 2007.

ANDRADE, A.B.; BOSI, M.L.M. Qualidade do cuidado em dois centros de atenção psicossocial sob o olhar de usuários. Saúde soc., São Paulo, v. 24, n. 3, p. 887-900, set. 2015. Disponível em: <http://www.scielo.br/scielo.php?pid=S0104$12902015000300887 \&$ script $=$ sci_abstract\&tlng $=\mathrm{pt}>$. Acesso em: 18 nov. 2019. Doi: http://dx.doi.org/10.1590/S0104-12902015131949.

BIRMAN, J.; COSTA, J. F. Organizações de instituições para uma psiquiatria comunitária. In: Amarante, P. (Org.). Psiquiatria social e reforma psiquiátrica. Rio de Janeiro: Fiocruz, 1994. p. 41-72

BORYSOW, I.C.; FURTADO, J.P. Acesso e intersetorialidade: o acompanhamento de pessoas em situação de rua com transtorno mental grave. Physis, Rio de Janeiro, v. 23, n. 1, p. 33-50, 2013. Disponível em: $<$ http://www.scielo.br/scielo.php?script=sci_arttext\&pid=S010373312013000100003\&lng=en\&nrm=iso>. Acesso em: 22 nov.

2019. Doi: http://dx.doi.org/10.1590/S0103-73312013000100003.

BRASIL. Lei Federal n. 10.216, de 06 de abril de 2001. Dispõe sobre a proteção e os direitos das pessoas portadoras de transtornos mentais e redireciona o modelo assistencial em saúde mental. Brasília, DF, 2001. Disponível em:

$<$ http://www.planalto.gov.br/ccivil_03/leis/leis_2001/l10216.htm>. Acesso em: 22 nov. 2019.

. Ministério da Saúde. Secretaria de Atenção à Saúde. DAPE. Coordenação Geral de Saúde Mental. Reforma psiquiátrica e política de saúde mental no Brasil. Documento apresentado à Conferência Regional de Reforma dos Serviços de Saúde Mental: 15 anos depois de Caracas. Brasília, DF, 2005. Disponível em:

$\langle$ http://bvsms.saude.gov.br/bvs/publicacoes/Relatorio15_anos_Caracas.pdf $>$. Acesso em: 22 nov. 2019.

Constituição da República Federativa do Brasil. Brasília, DF: Senado Federal, 1988. Disponível em: <http://www.planalto.gov.br/ccivil_03/constituicao/constituicao.htm>. Acesso em: 22 nov. 2019.

Decreto n. 7.053, de 23 de dezembro de 2009. Institui a Política Nacional para a População em Situação de Rua e seu Comitê Intersetorial de Acompanhamento e Monitoramento e dá outras providências. Brasília, DF, 2009. Disponível em: $<$ http://www.planalto.gov.br/ccivil_03/_ato2007-2010/2009/decreto/d7053.htm>. Acesso em: 22 nov. 2019.

Lei $\mathrm{n}^{\circ} 8.080$, de 19 de setembro de 1990. Dispõe sobre as condições para a promoção, proteção e recuperação da saúde, a organização e o funcionamento dos serviços 
correspondentes e dá outras providências. Brasília, 1990. Disponível em:

<http://www.planalto.gov.br/ccivil_03/leis/18080.htm>. Acesso em: 22 nov. 2019.

. Ministério da Saúde. Saúde da população em situação de rua: um direito humano.

Secretária de gestão estratégica e participativa. Brasília, 2014. Disponível em:

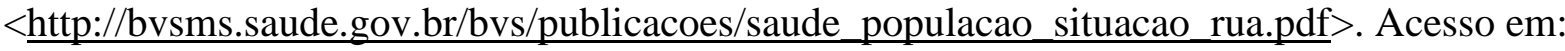
22 nov. 2019.

Ministério do Desenvolvimento Social e Combate à Fome. Orientações

técnicas: Centro de Referência Especializado para a População em Situação de Rua - Centro POP. SUAS e População em Situação de Rua, Volume 3. Brasília. Editora Brasil, 2011.

Disponível em:

< http://www.mds.gov.br/webarquivos/publicacao/assistencia_social/Cadernos/orientacoes_ce ntro_pop.pdf $>$. Acesso em: 22 nov. 2019.

FERRAZ, F.C. Andarilhos da imaginação: um estudo sobre os loucos de rua. Casa do Psicólogo, 2000.

FERRAZZA, D. D. A.; ROCHA, L. C. D.; LUZIO, C.

A. Medicalização em um serviço público de saúde mental: um estudo sobre a prescrição de psicofármacos. Gerais: Revista Interinstitucional de Psicologia, 255-65, 2013. Recuperado de https://repositorio.unesp.br/handle/11449/126847

FOUCAULT, M. A governamentalidade. In: Microfísica do poder. Rio de Janeiro: Graal, 1978. p. 277-293.

História da loucura: na idade clássica. São Paulo: Perspectiva, 2008.

LEONARDIS, O. "Estatuto y figuras de la peligrosidad social. Entre psiquiatría reformada y sistema penal: notas sociológicas. Revista de Ciencias Penales, 4, 429-449, 1998. Recuperado de https://dialnet.unirioja.es/servlet/articulo?codigo $=3681554$

LISBOA, M.S. Os loucos de rua e as redes de saúde mental: os desafios do cuidado no território e a armadilha da institucionalização. 2013. 290f. Tese (Programa de Estudos PósGraduados em Psicologia: Psicologia Social) - Pontifícia Universidade Católica de São Paulo, São Paulo, 2013. Disponível em: 〈https://sapientia.pucsp.br/handle/handle/17023〉. Acesso em: 22 nov. 2019.

LONDERO, M.F.P.; CECCIM, R.B.; BILIBIO, L.F.S. Consultório de/na rua: desafio para um cuidado em verso na saúde. Interface-Comunicação, Saúde, Educação, v. 18, p. 251-260, 2014. Doi: 10.1590/1807-57622013.0738

MAGNANI, J.G.C. De perto e de dentro: notas para uma etnografia urbana. Rev. bras. Ci. Soc., São Paulo, v. 17, n. 49, p. 11-29, jun. 2002. Disponível em: $<$ http://www.scielo.br/scielo.php?script=sci_arttext\&pid=S010269092002000200002\&lng=en\&nrm=iso>. Acesso em: 22 nov. 2019. Doi: http://dx.doi.org/10.1590/S0102-69092002000200002.

MERHY, E.E. Anormais do desejo: os novos não humanos? Os sinais que vêm da vida cotidiana e da rua. Conselho Federal de Psicologia. Grupo de Trabalho de Álcool e outras 
Drogas. Drogas e cidadania: em debate. Brasília: CFP, p. 9-18, 2012. Disponível em: <http://eps.otics.org/material/entrada-outras-ofertas/artigos/anormais-do-desejo-osnovos-nao-humanos/view>. Acesso em: 23 nov. 2019.

OLIVEIRA, R.C. O trabalho do antropólogo. São Paulo: Editora da Unesp, 1998.

PEIRANO, M. A favor da etnografia. Rio de Janeiro: Relume-Dumará. 1995.

SILVA, A.B. O cuidado ao usuário de crack: análise da concepção de território de trabalhadores de um CAPS AD. (Dissertação de Mestrado). Universidade Federal do Rio Grande do Sul. 2014. Disponível em: 〈https://www.lume.ufrgs.br/handle/10183/95385>. Acesso em: 22 de nov. 2019.

VARANDA, W.; ADORNO, R.C.F. Descartáveis urbanos: discutindo a complexidade da população de rua e o desafio para políticas de saúde. Saúde soc., São Paulo, v. 13, n. 1, p. 5669, abr. 2004. Disponível em:

$<$ http://www.scielo.br/scielo.php?script=sci_arttext\&pid=S010412902004000100007\&lng=en\&nrm=iso>. Acesso em: 22 nov.

2019. Doi: http://dx.doi.org/10.1590/S0104-12902004000100007.

YASUI, S.; COSTA-ROSA, A. A Estratégia Atenção Psicossocial: desafio na prática dos novos dispositivos de Saúde Mental. Saúde em debate, 32(78-79-80), 27-37, 2008.

Recuperado de https://www.redalyc.org/pdf/4063/406341773003.pdf

Data de recebimento: $24 / 07 / 2019$

Data de aceite: 14/11/2019

\section{Sobre as autoras:}

Eneida Santiago é Psicóloga (Unesp - Assis), Mestre em Psicologia e Sociedade e Doutora em Saúde Coletiva (Unesp-Assis). Atualmente é Professora Adjunta da Universidade Estadual de Londrina (UEL) no Departamento de Psicologia Social e Institucional e Docente do Programa de Pós Graduação Stricto Sensu em Psicologia (PPGP-UEL), além de ser Avaliadora Institucional do Ministério da Educação (MEC). Tem desenvolvido pesquisas na área de Psicologia, Processos de Trabalho e Saúde Coletiva, com ênfase em Saúde Mental e Coletiva, Psicologia e Políticas Públicas, Saúde e Processos de Subjetivação e Intersetorialidade, atuando principalmente nos seguintes temas: políticas públicas e gestão da vida, sistema prisional.. Endereço Eletrônico: ensantiagobr@yahoo.com.br

Lucielly Santos é Psicóloga, mestranda em Psicologia pela Universidade Estadula de Londrina (UEL). Endereço Eletrônico: luciellycs@gmail.com 